\title{
THE ANTI-EMETIC ACTION OF FLUOTHANE: \\ A COMPARATIVE STUDY IN OBSTETRICAL ANAESTHESIA
}

RALPh R. Novoa, M.D., A.P.b. \& s.o.e: (Spain) ${ }^{1}$

ALTHOUGH MODERN OBSTETRIC TECHNIQUES have considerably reduced the cause of maternal deaths owing to infection, toxaemia, and haemorrhage, anaesthetic procedures during labour and delivery are still the cause of many fatalities,according to recent statistics $(1,2)$.

Some of the most troublesome occurrences during obstetric anaesthesia are nausea, retching, and vomiting, of which vomiting can cause the most serious complications $(3,4)$. It is surprising how many publications have appeared on the subject of vomiting and its treatment during surgical and obstetric anaesthesia; but, to date, no drug, technique, or anaesthetic procedure has been found to prevent it.

The causes for the high incidence of vomiting during delivery are:

\section{Anaesthesia}

$\mathrm{O} .2$ deprivation

$\mathrm{CO}_{2}$ accumulation

Length of procedure

Operative site

Troublesome induction

Premedication

Anatomicophysiologic changes during pregnancy

Fulness of abdominal cavity

Compression and displacement of stomach

C.N.S. irritability

Alterations of the sympathetic and parasympathetic systems

Endocrine changes

Sudden onset of labour and rapid delivery with a full stomach

Emotional stress during delivery

Fear of delivery, especially in primiparae

Fear of the anaesthetic mask technique

Abnormal behaviour of mothers who do not want the baby

These are some of the factors which lead to yomiting during anaesthetic procedures.

Although the literature on Fluothane ${ }^{\circledR}$ is extensive, we have seen few reports so far about its use in obstetrics. This is surprising in view of the large number of anaesthetic services which are now evaluating Fluothane clinically as a substitute for chloroform or other agents in obstetrics (Table I).

In this paper we are reporting our experiences in 250 unselected deliveries, from July, 1958, to July, 1959, comparing Fluothane with Trilene ${ }^{\circledR}$ and cyclopropane from the point of view of its anti-emetic properties.

1Notre-Dame Hospital, Department of Anesthesia, Montreal, P.Q. 
TABLE I

\begin{tabular}{|c|c|c|c|c|c|c|c|c|c|}
\hline & \multirow{2}{*}{$\begin{array}{l}\text { No. of } \\
\text { cases }\end{array}$} & \multicolumn{4}{|c|}{ Anaesthetic agents } & \multicolumn{2}{|c|}{ Mortality } & \multicolumn{2}{|c|}{ Pelivery } \\
\hline & & Cyclopropane & Trilene & Fluothane & Others & Mother & Child & Normal & Forceps \\
\hline 1957 & 1541 & 130 & 964 & 0 & 447 & 0 & 44 & 1153 & 388 \\
\hline 1958 & 1521 & 225 & 353 & 397 & 546 & 0 & 31 & 1238 & 283 \\
\hline $1959^{*}$ & 759 & 55 & 53 & 478 & 173 & 0 & .23 & 596 & 163 \\
\hline
\end{tabular}

*January to July, 1959.

At present, we have under way another extensive study using the azeotropic mixture recommended by Hudon (5) which we found also reduces the incidence of vomiting. We are hoping to assess the racial emotional, constitutional, and nutritional factors which may cause vomiting during labour and delivery.

\section{TECHINIQUE}

We have used the technique described below in all cases, with slight variations, depending on the nervous state of the patient, type of obstetric procedure, and whether the case was an emergency.

We have used the standard English Bcyle's machine for all Fluothane anaesthesias with the Fluotec apparatus instead of the Trilene bottle, whereas for the other anaesthetic procedures we used the standard Ohio Heidbrink. The delivery of known concentrations is, of course, imperative to obtain good results with the use of this agent (6).

A transparent plastic mask is used so that the patient's mouth may be constantly observed for secretions, regurgitations, or silent vomiting. This is often difficult to observe during prolonged and severe uterine contractions. We use a'semi-open circle, with a Leigh valve near the patient's head and the bag near the open circle valve. The patient's head is always tilted backward and laterally; no pillow's are used. The delivery table is slightly in the Trendelenburg position. An aspiration machine with a rubber and metal sucker is placed near the anaesthetist.

The patient is instructed to breathe deeply and slowly with every painful contraction, and a mixture of nitrous oxide $(5-6 \mathrm{~L} . / \mathrm{min}$.) and oxygen $(2 \mathrm{~L} . / \mathrm{min}$.) is given intermittently at the end of the dilatation period. As soon as the perineum becomes prominent in primiparae, or the contractions severe and continuous in multiparae, Fluothane is added to the mixture (now $4 \mathrm{~L} . / \mathrm{min}$. of nitrous oxide and $2 \mathrm{~L} . / \mathrm{min}$. oxygen) in a concentration of 0.5 per cent for $1 \mathrm{~min}_{4}$, then increased to 0.9 up to 1.3 per cent in an average case; when the patient is excited or in great pain, the Fluothane concentration may be increased from 1.7 to 2.3 per cent, which is maintained for 4 to $6 \mathrm{~min}$. Afterwards anaesthesia is maintained with 0.6 to 0.9 per cent in the average patient.

When the baby's head emerges, Fluothane and nitrous oxide are stopped and a flow of 7 to $10 \mathrm{~L} . / \mathrm{min}$. of oxygen is given until the umbilical cord is clamped. After this, the procedure is started again as described above, if necessary, for repair or manual curettage. 
The patient wakens surprisingly quickly, is in most cases well oriented, and asks for the baby within a few minutes.

In the few cases where muscle relaxants are required, such as Brevidil or Anectine, Fluothane is reduced to 0.5 per cent while the anaesthetist controls respiration.

We always try to maintain the patient in the lightest anaesthetic plane possible, and if the contractions become less frequent, the concentration of Fluothane is decreased according to the requirements of the patient.

\section{Results}

This technique has been used in 250 unselected patients in labour,; and we have compared our results in reducing vomiting with our previous experiences with cyclopropane and Trilene (Table III). Every time we returned to the use of these latter two agents, we came to the same conclusion, which was corroborated by other anaesthetists of our service. The decreased incidence of vomiting following Fluothane justifies the use of this anaesthetic agent routinely in all cases of obstetric anaesthesia (Table I).

Our evaluation of vomiting is as follows: severe: repeatedly during delivery and post-delivery; medium: during delivery only (two or three times); mild: a small amount during delivery only (once).

Nausea and retching are considered a separate symptom complex. Nurses are instructed to record any kind of vomiting, nausea, or retching before, during, and after delivery over a period of 12 hours.

T.ABLE II

\begin{tabular}{lccc}
\hline \hline & \multicolumn{3}{c}{ Anaesthetic agent } \\
\cline { 2 - 4 } \cline { 3 - 4 } & Cyclopropane & Trilene & Fluothane \\
\hline Naternal mortality & 0 & 0 & 0 \\
Naternal morbidity & 2 & 3 & 3 \\
Foetal mortality & 5 & 2 & 4 \\
Foetal morbidity* & 8 & 6 & 11 \\
\hline
\end{tabular}

* lle include in this section all babies who needed any kind of supplementary therapeuric measure after birth.

All patients were premedicated, by their private doctors or obstetric staff, mainly with Demerol (50-75 mg.) every 4 to 6 hours; we always try to avoid giving drugs at least 2 hours before expected delivery. A barbiturate, either pentobarbital or Secobarbital, is usually added in an average dose of $100 \mathrm{mg}$. every 4-6 hours. The longest procedure was 1 hour, 45 min., and the shortest 15 min.

In our series we had seven cases of vomiting in spite of Fluothane. In three of these we do not believe that Fluothane was the cause. The first woman was delivered of a six-month-old dead foetus, Rh negative. The second woman was 
admitted with the knowledge that the baby was dead; she was upset, nervous, and crying. The third case was a woman who had emotional and moral problems concerning her pregnancy, and she vomited during induction.

The effect of Fluothane in reducing vomiting compared to Trilene and cyclopropane as shown in Table III is evident. Although our series is small, our results correspond to those obtained by other authors who have used Fluothane in obstetrics $(7,8)$ and in other fields of surgery $(9,10,11)$.

T.ABI.F. III

\begin{tabular}{|c|c|c|c|c|c|c|}
\hline Anaesthêtic agent & $\begin{array}{l}\text { No. of } \\
\text { cases }\end{array}$ & Severe & $\begin{array}{l}\text { Vomiting } \\
\text { Medium }\end{array}$ & Mild & $\begin{array}{l}\text { Retching } \\
\text { and nausea }\end{array}$ & $\begin{array}{c}\text { Vomiting } \\
\left(\begin{array}{c}0 \\
(0)\end{array}\right)\end{array}$ \\
\hline $\mathrm{N}, \mathrm{O}$ and $\mathrm{C}_{3} \mathrm{H}_{6}$ & 50 & 0 & 4 & 17 & 13 & 42.0 \\
\hline $\mathrm{N}_{2} \mathrm{O}$ and Trilene & 50 & 0 & 1 & 13 & 10 & $2 \varepsilon .0$ \\
\hline $\mathrm{N}_{2} \mathrm{O}$ and Fluothane & 1.50 & 0 & 3 & 4 & 8 & 4.6 \\
\hline Totals & 250 & 0 & 8 & 34 & 31 & 16.8 \\
\hline
\end{tabular}

We have not seen any serious complications in our series which could be attributed to Fluothane (Table II) and no other therapeutic measures had to be carried out in any patient. One woman had a fall in blood pressure after long labour and uterine haemorrhage which required manual curettage and extraction of the placenta, but she was well controlled with blood transfusions and was awake at the end of the procedure without evidence of vomiting or excitation. Fluothane was not discontinued in this case.

We had no complaints from the obstetricians regarding uterine relaxation or bleeding, and they were satisfied with our technique. From the point of view of the baby, as shown in Table II, Fluothane appears to be safe and certainly not more dangerous than other agents. We have not seen any apnoea or depression of clinical significance. The patients were able to take fluids after $2-4$ hours post partum, were wide awake and quiet, and few had to forego their regular meals.

TARLE N

\begin{tabular}{|c|c|c|c|c|c|c|}
\hline \multirow[b]{2}{*}{ Operation tirine } & \multirow{2}{*}{$\begin{array}{l}\text { Yo. of } \\
\text { castes }\end{array}$} & \multicolumn{3}{|c|}{ Comiting } & \multirow{2}{*}{$\begin{array}{l}\text { Retching } \\
\text { and nausea }\end{array}$} & \multirow{2}{*}{$\begin{array}{c}\text { Vomiting } \\
(\%)\end{array}$} \\
\hline & & Severe & Medium & Nild & & \\
\hline Ip to $15 \mathrm{~min}$. & 46 & 0 & 3 & 11 & 13 & $30+4$ \\
\hline 15 to 30 mins. & $\$ 1$ & i) & 2 & 8 & 5 & 12.3 \\
\hline 30 mins to $1 \mathrm{hr}$. & 14 & 0 & () & 9 & !) & 9.5 \\
\hline Nore than $1 \mathrm{hr}$. & 29 & 0 & 3 & 6 & 4 & 31.0 \\
\hline TUTALS & 250 & 0 & 8 & 34 & 31 & 168 \\
\hline
\end{tabular}

As shown in Table $\mathbb{I}$, vomiting seems to occur more frequently during long procedures and when rapid induction is required. In our experience, however, when Fluothane is used in the manner described above (Tables V, VI), its antiemetic actirn was also shown during long procedures and when different operating techniques were employed. 
11. Its rapid elimination brings quick recovery even after prolonged operations, producing less nausea and retching. Patients experience no gastric discomfort as caused by other agents and no routine anti-emetic medication has to be given. If present, it is so negligible that no therapy is required.

12. The organoleptic characteristics of Fluothane are well within the tolerance margin of normal persons.

13. As Fluothane is eliminated unchanged through the lung, no metabolic changes occur during the complicated metabolic process of labour.

14. Patients who have been induced during states of excitement, crying or fighting because of fear, generally awake calmed, happy, and in good physical condition.

15. As Fluothane does not appear to be a vagal stimulant, coughing and other reflexes which may induce vomiting are not stimulated.

Among the disadvantages of Fluothane anaesthesia in obstetrics are:

1. Trained, skilful anaesthetists are needed.

2. A special vaporizer is needed.

3. It is expensive for general use.

4. It has a reported depressant action on the respiratory and circulatory systems. (Patients coming to the delivery room are usually healthy and rarely have any cardiac or respiratory complications.)

It must be emphasized that Fluothane and the technique attending its use are recommended for trained personnel. Blood pressure, pulse, heart rate, and rhythm must be frequently checked, especially in the delivery room where confusion often exists owing to emergencies and the tense atmosphere inevitable during delivery. Fluothane is a very potent agent and the use of a calibrated vaporizer and constant observations are obligatory.

\section{SUMMARY}

This paper presents a comparison between the anti-emetic properties of Fluothane, Trilene, and cyclopropane during obstetrical anaesthesia in 250 unselected deliveries.

A marked reduction in the incidence of vomiting during obstetrical anaesthesia has been obtained with the use of controlled concentrations of Fluothane (Fluotec apparatus) and a low percentage of this agent. The advantages and disadvantages of Fluothane in obstetrical anaesthesia are enumerated and the tabulated results are self-evident.

\section{ACKNOWLEDGMENT}

I should like to acknowledge the help of Dr. Leighton Smith, Medical Director of Ayerst, McKenna \& Harrison, in correcting the English translation of this paper.

\section{RÉSUMÉ}

Dans ce travail, nous comparons les propriétés anti-émétiques de Fluothane, de Trilène et du cyclopropane dans 250 cas d'accouchements non sélectionnés, 
au point de vue de la diminution de l'incidence de, vômissements par l'emplòi de Fluothane.

Les résultats obtenus dépendent de l'administration adéquate de Fluothane, du matériel et de la technique employés. Une basse concentration de Fluothane et l'emploi d'un appareil Fluotec sont, de façon marquée, les principales causes des résultats qui s'obtiennent.

Les avantages et désavantages de l'anesthésie au Fluothane en obstétrique et les résultats énumérés aux tableaux de cet ouvrage sont suffisamment éloquents.

\section{REFERENCES}

1. A.M.A. Fundamentals in Anesthesia, 3rd ed. New York: Saunders (1954).

2. Girbert, R. G. B. Reflections of Medical Developments upon Anesthesia. Medical Services J. Canada 4: 248 (April, 1959).

3. Marshill, B. M., \& Gordon, R. A. Vomiting, Regurgitation and Aspiration in Anaesthesia, I. Canad. Anaesth. Soc. J. 5: 274 (July, 1958).

4. Marshald, B. M., \& Gordon, R. A. Vomiting, Regurgitation and Aspiration in Anaesthesia,' II. Canad. Anaesth. Soc. J. 5: 438 (Oct., 1958).

5. Hudon, F., Jacques, A., \& Borvin, P. A. Fluothane-Ether: An Azeotropic Mixture. Canad. Anaesth. Soc. J. 5: 403 (Oct., 1958).

6. MacKay, I. M., \& Kalow, W. A. A Clinical and Laboratory Evaluation of Four Fluothane Vaporizers. Canad. Anaesth. Soc. J. 5: 248 (July, 1958).

7. Cutrer, J. A., \& King, B. D. The Use of Fluothane in Obstetrical Anesthesia. New York: Med. Soc. Anesth. Section (May, 1959).

8. Sheridan, C. A., \& Robson, J. C. Fluothane in Obstetrical Anesthesia: A Report from the Department of Anesthesia, Royal Victoria Hospital, Montreal.

9. Robson, J. G., \& Sheridan, C. A. Preliminary Investigation with Fluothane, Anesth. and Analg. 5: 62 (Sept., 1957).

10. Brennan, H. J., Hunter, A. R., \& Johnstone, M. Halothane: A Clinical Assessment. Lancet II, 453-457' (Sept., 1957).

11. McAlpine, D. F., \& Bovering, M. W. Anaesthesia for Tonsillectomy and Adenoidectomy in Children. Canad. Anaesth. Soc. J. 5: 61 (Jan., 1958). 